\title{
\#6
}

\section{Penerapan Mobile Journalism pada Live Report Pemilu Presiden Amerika Serikat dengan Memanfaatkan Fitur Live Instagram}

Diyah Ayu Karunianingsih

Berita tentang pemilihan umum apalagi pemilu presiden selalu menjadi berita hard news yang manarik. Bukan hanya menarik bagi media dan jurnalis untuk meliput namun juga menarik bagi masyarakat. Hal ini karena pemilu presiden memiliki news value yang tinggi, dan berdampak baik dalam skala nasional maupun global.

Tahun 2020 merupakan salah satu tahun bersejarah bagi Amerika Serikat. Tahun 2020 merupakan perayaan pesta demokrasi pemilihan Presiden Amerika Serikat ke 46 yang diikuti oleh 50 negara bagian di seluruh Amerika Serikat. Pemilu Presiden Amerika Serikat dilaksanakan tanggal 3 November 2020, dengan dua calon 
presiden dan calon wakil presiden yaitu Donald Trump dan Mike Pence yang diusung oleh Partai Republik dan rivalnya Joe Biden dan Kamala Haris yang diusung oleh Partai Demokrat.

Laporan berita perkembangan pelaksanaan pemilu dan penghitungan suara hasil pemilu menjadi berita yang dinanti. Hasil final pemungutan suara dan proses inaugurasi presiden dan wakil presiden terpilih yang memenangkan pemilu juga ditunggu masyarakat, bahkan setiap detik, menit dan jam, perkembangannya selalu menarik dan ingin diketahui oleh masyarakat, terutama masyarakat Amerika Serikat. Apalagi dalam prosesnya, pemilu presiden tahun 2020 tidak semulus yang diharapkan karena Donald Trump sempat tidak menerima kekalahannya atas Joe Biden. Disisi lain juga dinantikan masyarakat global, karena hasil pemilu presiden nantinya berkaitan dengan kebijakan-kebijakan presiden terpilih yang berpengaruh terhadap hubungan antar negara dan kebijakan lainnya yang berdampak global.

Perkembangan pemilu sampai pasca pemilu menjadi berita yang penting dan dibutuhkan oleh masyarakat. Jurnalis perlu hadir untuk memantau dan melaporkan proses pemilu dan penghitungan suara, serta melaporkan peristiwa-peristiwa yang terjadi dan perlu diketahui masyarakat, artinya memiliki news value bagi masyarakat. Jurnalis dari seluruh dunia terus melaporkan perkembangan situasi, proses pelaksanaan pemilu dan penghitungan suara dari sejumlah negara bagian di Amerika Serikat tahun 2020. Jurnalis menggunakan berbagai medium seperti radio, televisi, portal berita dan berbagai media sosial untuk menyampaikan berita terbaru (news update).

Kemajuan teknologi dan perkembangan jurnalistik online begitu pesat, didukung fitur-fitur media sosial yang dapat dimanfaatkan untuk proses kerja jurnalistik. Teknik produksi berbasis mobile journalism (jurnalisme seluler) juga diterapkan, dengan memanfaatkan smartphone untuk memproduksi dan melaporkan 
berita. Media baru dan mobile journalism (disingkat: mojo) memungkinkan bagi jurnalis untuk melaporkan berita lebih cepat dibandingkan media cetak, radio ataupun televisi. Hal ini karena dengan mobile journalism, jurnalis memungkinkan dapat langsung melaporkan berita menggunakan smartphone yang ada di genggaman mereka dan langsung dapat mengunggahnya pada platform media sosial yang digunakan.

Kemajuan teknologi semakin memudahkan proses produksi dan publikasi berita sehingga berita dapat lebih cepat diakses oleh masyarakat bahkan real time. Berbekal smartphone, alat yang berukuran kecil dan dapat disimpan di saku (pocket size), menjadi terobosan baru cara melakukan kegiatan jurnalistik yang dikenal dengan jurnalisme seluler. Dengan Jurnalisme seluker/mobile journalism, jurnalis tidak perlu khawatir lagi tentang pengaturan kabel, pengaturan kamera, pengaturan koneksi dan transmisi satelit, cukup dengan teknologi smartphone yang merupakan alat multi fungsi (multifunctional device) dan internet maka dapat memproduksi sekaligus mempublikasikan laporan beritanya dimanapun dan kapanpun. Teknologi smartphone dan internet mampu meningkatkan mobilitas dan akses para jurnalis.

Mobile Journalism atau jurnalsime seluler menurut Burum \& Quinn yang dikutip dari Lydersen (2020) adalah bentuk pelaporan yang inovatif, dimana orang hanya menggunakan ponsel cerdas untuk melakukannya, membuat dan mengajukan cerita, dapat berupa video, audio, slideshow, foto atau teks. Kemudian The Mobile Journalism Manual dalam Westlund yang dikutip oleh Lydersen (2020) merupakan sebuah platform online untuk reporter dan redaksi berita, menjelaskan ponsel sebagai "studio produksi di saku anda". Definisi mobile journalism jika dilihat dari pendekatan fungsi dan karakter teknologi ini menunjukkan bahwa mobile journalism merupakan inovasi teknologi yang praktis, lebih mudah, dan lebih 
murah bagi para jurnalis dalam melakukan praktek jurnalistik untuk melaporkan berita dengan berbagai bentuk penyajian.

Mobile Journalism menurut Maccise \& Marai dalam Alajazeera Media Training \& Development Centre adalah proses pengumpulan dan penyampaian berita menggunakan smartphone atau tablet yang menjadi tren peliputan yang berpotensi menjadi standar baru dalam praktik jurnalistik khususnya laporan breaking news. Mark Jones, editor Reuters breaking news service, News Alert dalam Quinn (2012) mengatakan bahwa perusahaan berusaha menuju ke masa depan, "We were thinking about new ways to report", perannya adalah agar lebih tersedia bagi penonton dan memberikan teknologi yang portable dan fleksibel bagi jurnalis.

Alfarest dalam Lydersen (2020) mendefinisikan mobile journalism sebagai "all journalistic practices that involve the use of mobile devices (such us tablets or smartphone)". Alfarest memisahkan antara mobile journalism dengan konten video pribadi dan konten media sosial pribadi. Alfarest menyebut hanya karena siapapun dapat menggunakan ponsel cerdas untuk menghasilkan cerita, bukan berarti bahwa setiap orang yang memproduksi cerita di smartphone mendapat label mobile journalism. Namun Alfarest mendefinisikan mobile journalism sebagai sebuah praktek profesional yang hadir dalam berbagai bentuk dan muncul dalam beragam format dan publikasi (Lydersen, 2020).

Mobile journalism dilakukan oleh para jurnalis untuk menghasilkan laporan berita yang ditujukan bagi segmentasi audiens yang menggunakan mobile devices dalam mengonsumsi informasi (mobile journalism for mobile audience). Dalam tulisan ini, pembahasan difokuskan pada penerapan mobile journalism yang dilakukan para jurnalis dalam melaporkan berita dengan memanfaatkan fitur live instagram untuk melakukan laporan langsung dari lokasi peristiwa (live report). Fitur live instagram menjadi alternatif bagi para jurnalis untuk melakukan live report 
karena instagram memiliki audiens nya sendiri, yaitu pengguna aktif instagram.

Data tren pengguna internet dan media sosial per Januari tahun 2020 di dunia menurut Hootsuit (We Are Social): Indonesia Digital Report 2020 menunjukkan dari total populasi di dunia sebanyak 7,75 milyar, sebanyak 5,19 milyar merupakan pengguna unique mobile phone user, sebanyak 4,54 milyar merupakan pengguna internet (internet user), dan sebanyak 3,80 milyar penduduk di dunia merupakan pengguna aktif media sosial (active social media user).

Sementara Global Digital Growth dari Januari 2019 ke Januari 2020, menurut laporan Hootsuit (We Are Social): Indonesia Digital Report 2020, jumlah populasi bertumbuh lebih dari 1,1 persen atau lebih dari 82 juta, sedangkan pertumbuhan pengguna unique mobile phone users sebesar lebih dari 2,4 persen atau lebih dari 124 juta. Sementara pertumbuhan pengguna internet sebesar lebih dari 7 persen atau lebih dari 298 juta, dan pengguna aktif media sosial bertumbuh lebih dari 9,2 persen atau lebih dari 321 juta. Dari data ini menunjukkan bahwa jumlah pengguna internet dan pengguna media sosial aktif meningkat cukup signifikan dalam satu tahun.

Sementara jika dilihat dari pengguna media sosial, data peringkat pengguna media sosial dunia berdasar laporan Hootsuite (we are social): Indonesia Digital Report 2020 (data terbaru per 25 Januari 2020) adalah peringkat pertama Facebook dengan jumlah 2.449 juta pengguna, peringkat kedua Youtube dengan jumlah 2.000 juta pengguna, peringkat ketiga WhatsApp dengan jumlah 1.600 juta pengguna, FB Messenger sebanyak 1.300 juta pengguna, Wechat sebanyak 1.151 juta pengguna, Instagram sebanyak 1.000 juta pengguna sedangkan Tiktok sebanyak 800 juta pengguna. Data pengguna media sosial ini menunjukkan bahwa media sosial memiliki audiens tersendiri di setiap platform, termasuk instagram. 
Penetrasi pengguna media sosial ini menjadi peluang bagi media massa dalam memilih media yang akan digunakan untuk publikasi berita. Salah satunya adalah media sosial instagram. Media sosial instagram merupakan media yang banyak diminati dan diunduh oleh pengguna smartphone di dunia. Jika dilihat dari pengguna aktif instagram, berdasar laporan We Are Social yang dikutip dari lokadata, menyebut data negara pengguna instagram terbanyak di dunia per Januari 2019 adalah Amerika Serikat, diikuti oleh India, Brazil dan Indonesia (gambar 1). Pada tahun 2019 Amerika Serikat berada di posisi pertama pengguna instagram dengan jumlah 120 juta pengguna. Data tersebut menunjukkan bahwa di Amerika Serikat, instagram menjadi media sosial yang digemari.

\section{Gambar 1. Negara Pengguna Instagram Terbanyak di Dunia}

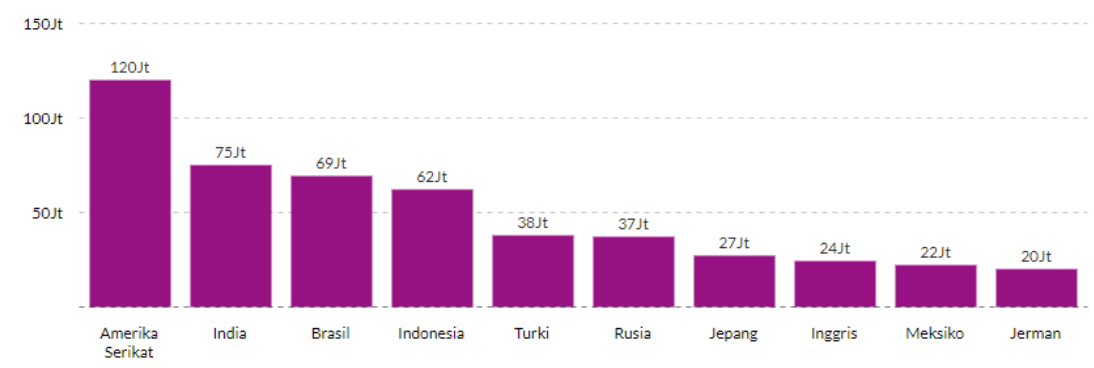

Sumber: Lokadata (2019)

Jika membedah data pengguna instagram di Ameraika Serikat, Jumlah pengguna Instagram di Amerika Serikat per Januari 2020 (Napoleon.Cat, 2020) sebanyak 119.700 .000 pengguna yaitu 35,8 persen dari jumlah total populasi. Dari data pengguna Instagram tersebut, sebanyak 55,9 persen merupakan pengguna perempuan dan 44,1 persen adalah pengguna laki-laki. Data tersebut juga menunjukkan bahwa pengguna terbesar Instagram berusia 25 sampai 34 tahun (gambar 2). 
Gambar 2. Data Pengguna Instagram Aktif di Amerika Serikat, Januari 2020

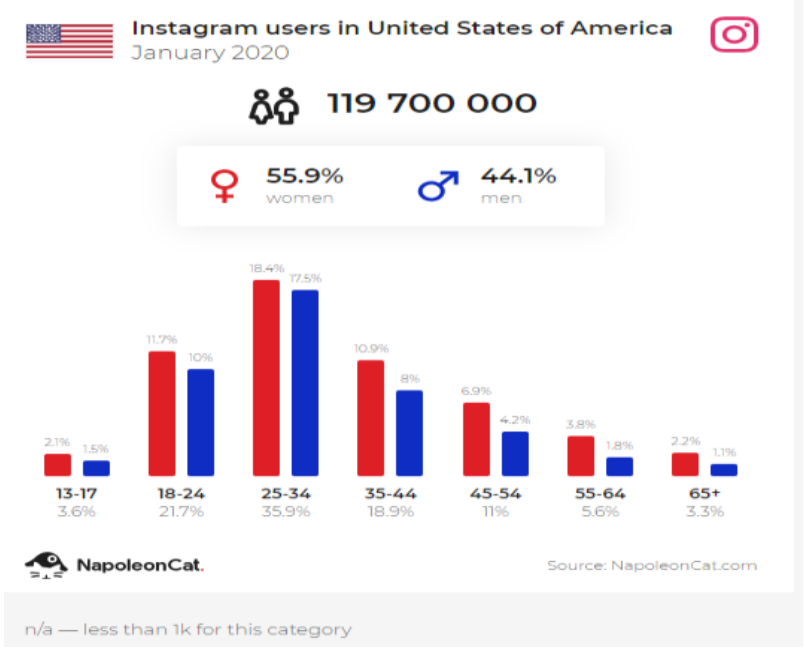

Sumber: Napoleon.Cat (2020)

Dengan jumlah pengguna aktif Instagram yang besar, menjadi pasar audiens bagi pemberitaan media. Karakter media sosial instagram yang dikonsumsi menggunakan smartphone pun identik lebih dekat dan bersifat privat bagi pengguna aktif Instagram karena dikonsumsi melalui smartphone yang merupakan barang pribadi. Hal ini kemudian menjadi potensi yang baik untuk dimanfaatkan sebagai media publikasi berita dengan sasaran pengguna aktif media sosial Instagram. Salah satunya adalah publikasi beritaberita pada masa pemilu presiden Amerika Serikat ke 46 tahun 2020.

\section{Teknologi Mobile Journalism sebagai Media}

\section{Alternatif Live Report}

Secara umum, reportase merupakan laporan berita yang disampaikan oleh jurnalis, baik laporan berupa tulisan untuk media cetak, laporan dalam bentuk audio untuk berita radio, rekaman video untuk berita televisi atau laporan multimedia untuk media baru. Jika dilihat dengan pendekatan media elektronik, maka 
reportase identik dengan laporan berita dalam format audio atau video yang disampaikan langsung atau rekaman oleh jurnalis di lokasi peliputan. Hal ini karena dalam konsep berita elektronik ada berbagai format penyajian berita, dan reportase menjadi salah satu format penyajian berita. Selanjutnya dalam media penyiaran, reportase dapat dilakukan dalam 2 cara, yaitu: 1) reportase secara taping (live on tape) yaitu rekaman reporter langsung dari lokasi kejadian namun tidak langsung disiarkan; 2) reportase secara live atau langsung dari lokasi kejadian (live report) dan disiarkan saat itu juga dari lokasi kejadian.

Kedua format reportase dalam pendekatan media eletronik televisi ini kemudian dapat diadopsi dan dilakukan untuk produksi reportase yang dipublikasikan menggunakan media Instagram. Menariknya adalah ketika jurnalis menerapkan mobile journalism dalam produksi berita maka mulai dari peliputan, wawancara, merekam gambar, sampai editing video bahkan live report dapat dilakukan oleh reporter menggunakan smartphone. Teknologi smartphone dan internet semakin memudahkan bagi para jurnalis untuk melakukan live report dengan peralatan dan persiapan yang lebih sederhana.

Instagram merupakan salah satu media sosial yang memberikan fasilitas live Instagram bagi semua pengguna Instagram. Media massa kemudian memanfaatkan fitur ini untuk melakukan reportase langsung (live report) berbasis mobile journalism. Memahami platform media sosial Instagram, fitur yang digunakan untuk publikasi berita bukan hanya instagram stories, Instagram feed, video IGTV, namun juga live Instagram. Fitur live Instagram ini memungkinkan bagi para jurnalis melaporkan berita dalam bentuk laporan langsung dari lokasi kejadian dimanapun dan kapanpun dengan menggunakan smartphone secara real time.

Dengan fitur live Instagram maka jurnalis melakukan live report berita kapanpun, dimanapun dan dari manapun dengan lebih 
mudah dibanding reportase langsung oleh media penyiaran televisi yang harus menggunakan OBVan dan jaringan satelit. Media baru berbasis internet dan media sosial instagram memudahkan bagi jurnalis untuk melaporkan berita dengan biaya yang lebih murah, persiapan peralatan yang lebih sederhana, serta tidak membutuhkan tim produksi terlalu banyak seperti siaran langsung menggunakan OBVan. Jika dilihat dari durasi, maka live Instagram memiliki durasi yang lama mencapai maksimal 60 menit dan apabila masih kurang, maka dapat meneruskan dengan memulai kembali live Instagram. Gambaran perkembangan teknologi ini menunjukkan bahwa teknologi Mobile Journalism menjadi media alternatif live report yang dapat dimanfaatkan oleh para jurnalis dengan sasaran audiens pengguna Instagram.

\section{Penerapan Mobile Journalism pada Live Report Pemilu Presiden Amerika.}

Media sosial kini merupakan media alternatif dalam publikasi berita. Namun demikian besar kemungkinan pada masa mendatang, media baru dan media sosial mulai akan lebih banyak dimanfaatkan untuk publikasi berita. Salah satu faktor yang mempengatuhi secara signifikan adalah beralihnya moda konsumsi berita oleh masyarakat. Orang mengonsumsi berita justru banyak melalui media baru dan media sosial dibanding media konvensional. Oleh karena itu untuk mengejar segmentasi mobile audiens, maka jurnalis juga dituntut beralih menggunakan media baru dan media sosial untuk penyampaikan beritanya. Contoh penerapan mobile journalism dengan memanfaatkan media sosial untuk melakukan live report adalah laporan langsung seputar Pemilu Presiden Amerika Serikat tahun 2020. Beberapa media massa yang memanfaatkan fitur live Instagram untuk melakukan live report, diantaranya: 


\section{ABC (American Broadcasting Company)}

Salah satu media internasional yang memanfaatkan fitur live Instagram dalam melakukan live report untuk melaporkan seputar pemilu presiden Amerika Serikat tahun 2020 adalah American Broadcasting Company $(A B C)$ News. Meski namanya broadcasting namun media ini juga menggunakan media baru untuk produksi dan publikasi beritanya.

Reportase langsung dilakukan jurnalis $A B C N e w s$ untuk publikasi media sosial Instagram pada akun @abcnews. Live report situasi pemilu Presiden Amerika Serikat dengan menerapkan mobile journalism dengan memanfaatkan fitur live Instagram dilakukan pada tanggal 4 November 2020. Jumlah penonton live Instagram sebanyak 741 pengguna (gambar 3). Usai live report menggunakan fitur live Instagram, selanjutnya agar pengguna Instagram yang belum sempat menonton live report tetap dapat menonton, maka live report tersebut kemudian diunggah kembali pada fitur IGTV.

Gambar 3. Live report jurnalis ABC menggunakan live Instagram

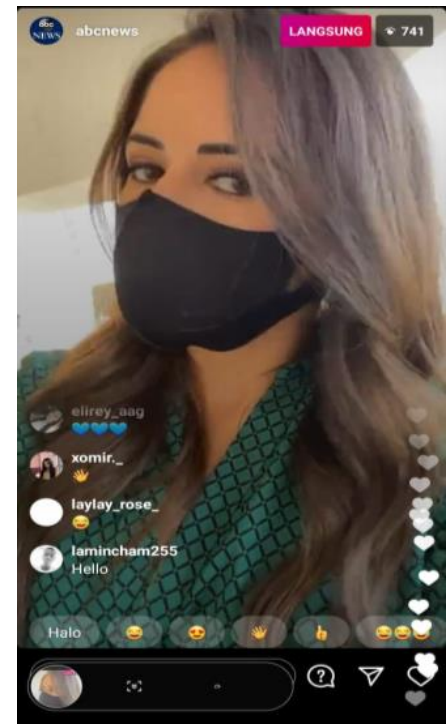

Sumber: tangkapan layar live Instagram @abcnews (2020) 
Dalam reportase langsung berdurasi 9 menit 5 detik diawali dengan penggunaan kata "hi guys" untuk menyapa audiens. Pilihan bahasa yang digunakan jurnalis $\mathrm{ABCNews}$ pada saat live report tidak terlalu formal, tidak seperti bahasa formal yang cenderung digunakan ketika live report untuk berita televisi. Selain bahasa, karakter dan gaya reportase jurnalis dalam menyampaikan laporan cenderung tidak terlalu formal, misalnya dari bahasa tubuh yang lebih santai. Bahkan jika ditinjau dari kualitas visual, sering terjadi gambar dengan komposisi yang kurang baik atau gambar goyang. Namun demikian karena karakter live Instagram dilakukan sendiri maka kualitas visual ini dimaklumi. Hal ini karena secara teknis live report menggunakan live Instagram yang dilakukan jurnalis ABCNews dilakukan dengan memegang sendiri kamera smartphone di tangannya (mobile journalism). Karakter media sosial dan televisi memang berbeda, misalnya dilihat dari gaya komunikasi pengguna Instagram (pengguna media sosial) yang cenderung menggunakan bahasa tidak terlalu formal dalam berkomunikasi. Selain itu juga disebabkan karakter pengguna Instagram di Amerika Serikat yang paling besar berusia 25 - 34 tahun, sehingga memungkinkan penggunaan bahasa informal dapat lebih mudah diterima oleh audiens Instagram. Gambaran ini menunjukkan bahwa terjadi beberapa perubahan/pergeseran karakter dalam melakukan live report dari karakter live report menggunakan media televisi yang cenderung formal ke media sosial yang memungkinkan cenderung lebih santai.

\section{NBCNews}

Media lain yang melakukan live report menggunakan fitur live instagram adalah National Broadcasting Company (NBC) News. Live report dilakukan NBCNews melalui akun Instagram @nbcnews. Salah satu live report yang dilakukan jurnalis NBCNews adalah live report tanggal 4 November pada jam 9.03 WIB dengan menerapkan mobile journalism dari smartphone reporternya. Topik reportase 
yang dilaporkan adalah kondisi dan situasi saat pemilu presiden AS berdurasi 5 menit 39 detik.

Mobile Journalisme menggunakan smartphone memiliki karakteristik yang berbeda dibanding live report menggunakan OBVan yang perlu memperhatikan panjang kabel dan kamera besar sehingga membatasi gerak jurnalis/reporter. Menariknya live report menggunakan smartphone di live Instagram dapat dilakukan dengan berjalan jauh dan skope visual lebih luas dari pada menggunakan kamera broadcast (OBVan). Reportase memanfaatkan live Instagram dapat berpindah-pindah lokasi sejauh kebutuhan reporter berjalan untuk memberikan observasi visual langsung pada saat itu (current times) seperti yang dilakukan jurnalis NBCNews. Peralatan smartphone yang portable lebih mudah digunakan dan dibawa berpindah tempat bahkan untuk live report di malam hari (gambar 4). Selain itu untuk memindah gambar antara wajah reporter dan objek liputan yang diberitakan sangat mudah hanya menekan tombol pindah kamera di smartphone yaitu kamera depan dan kamera belakang.

Gambar 4. Live report jurnalis NBCNews menggunakan live Instagram

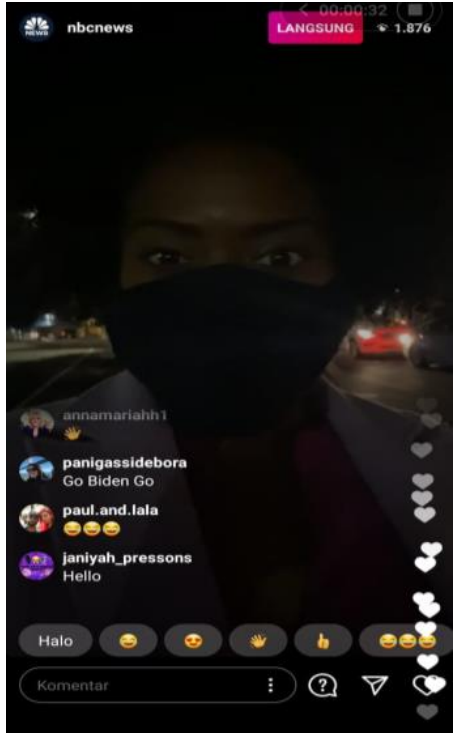

Sumber: Tangkapan layar live Instagram @nbcnews (2020) 
Pada gambar 4, diketahui jumlah penonton yang bergabung dalam live Instagram @nbcnews sebanyak 1.876 pengguna Instagram. Jumlah tersebut merupakan jumlah yang cukup signifikan, artinya segmentasi media sosial pengguna instagram cukup signifikan yang mengonsumsi berita menggunakan instagram.

Karakter fitur live Instagram yang menyediakan kolom komentar pagi pengguna instagram yang tergabung dalam live Instagram juga menjadi kelebihan tersendiri. Dengan kolom komentar tersebut mewadahi pengguna instagram untuk menyampaikan opini, komentar, dukungan atau sekedar menyapa (gambar 4). Hal ini menunjukkan bahwa kolom komentar menjadi media yang bersifat demokratis. Selain itu fitur tanda cinta (love) juga disediakan sebagai wadah bagi pengguna instagram yang ingin memberikan respon sebagai bentuk menyukai live Instagram tersebut. Fitur ini menjadi kelebihan karena memberikan ruang bagi pengguna untuk berinteraksi dalam bentuk apresisasi menyukai (love).

\section{VOA Indonesia}

Berdasar laporan Hootsuite (we are social): Indonesia Digital Report 2020 (data terbaru per 25 Januari 2020), Instagram merupakan media sosial terbanyak peringkat 4 yang digunakan masyarakat Indonesia, setelah Youtube, WhatsApp dan Facebook. Pengguna aktif ini pada rentang usia 16 - 64 tahun. Selain itu jika melihat Instagram Audiens Overview, jumlah pengguna Instagram yang dapat diraih iklan per Januari 2020 sebanyak 63 juta, hal ini sangat potensial jika media instagram digunakan sebagai media publikasi berita untuk meraih segementasi audiens di Indonesia (We Are Social, 2020).

Voice of Amerika (VOA) Indonesia memanfaatkan fitur live Instagram sebagai medium untuk melakukan live report, melaporkan kondisi pemilu presiden Amerika Serikat. Sebagai 
contoh live report tanggal 4 November 2020 jam 07.18 WIB, menerapkan reportase langsung gabungan beberapa jurnalis di beberapa tempat. Reportase langsung pertama (gambar 5) dilakukan oleh dua orang reporter yang menjadi reporter utama (anchor), berlokasi di depan Plaza Black Lives Matter berseberangan dengan Gedung Putih di Washington DC. Live report melaporkan situasi masyarakat yang berdatangan untuk "nobar" (nonton bareng) proses penghitungan suara pilpres Amerika Serikat dan semarak demokrasi warga Amerika Serikat.

Reportase berlanjut kepada reporter ke dua yang berada di dalam gedung putih untuk melaporkan kondisi di sekitar Gedung Putih, Presiden Donald Trump dan membahas tentang cara pilpres di AS. Live report bersama di dua lokasi dalam tampilan double frame menjadi kelebihan fitur live Instagram yang juga memungkinkan terjadi tanya jawab antar jurnalis (gambar 6). Live report berlanjut dengan reporter ke tiga di Los Angeles, melaporkan kondisi pemilu di salah satu TPS yang dilaksanakan di Staples Center yang juga menampilkan double frame dan tanya jawab (gambar 7). Target sasaran live report VOA Indonesia adalah pengguna aktif Instagram (follower @voaindonesia) di Indonesia dan beberapa negara di Asia Tenggara, sehingga penyampaian laporan menggunakan Bahasa Indonesia.

Durasi total live report yang dilakukan para jurnalis VOA Indonesia yaitu 42 menit 8 detik. Pada saat live report, jurnalis VOA menerapkan reportase secara estafet dari beberapa lokasi, dengan reporter utama di kawasan Washington DC. Fitur live Instagram memungkinkan adanya double frame, maka memungkinkan dua reporter melakukan reportase bersamaan dan saling berkomunikasi untuk berbagi informasi mengenai situasi dan kondisi di masing-masing lokasi, dimana reporter melaporkan (gambar 6 dan 7). 
Gambar 5. Live report jurnalis VOA Indonesia menggunakan live Instagram

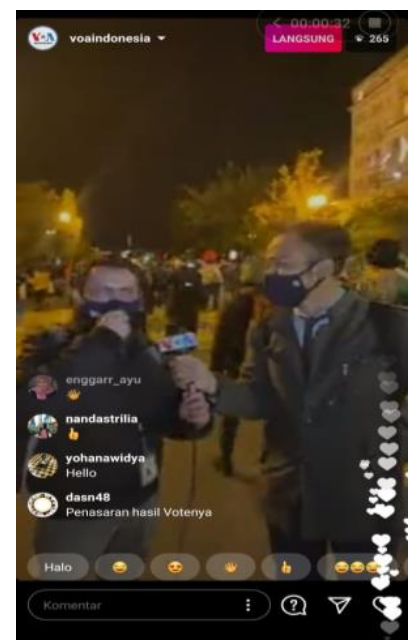

Sumber: Tangkapan layar live Instagram @voaindonesia (2020)

Pada gambar 5 jurnalis menerapkan mobile journalism. Peralatan yang digunakan adalah smartphone, unidirectional microphone cable, dan tripot agar memungkinkan pengaturan jarak antara kamera pada smartphone dengan jurnalis, sehingga dua jurnalis dapat berada dalam satu frame live instagram. Sedangkan reporter di Los Angeles dan White House menerapkan mobile jurnalisme dengan menggunakan peralatan lebih sederhana lagi yaitu smartphone, headset bawaan handphone dan tongsis. 
Gambar 6. Live report bersama di dua lokasi Plaza Black Lives Matter dan White House

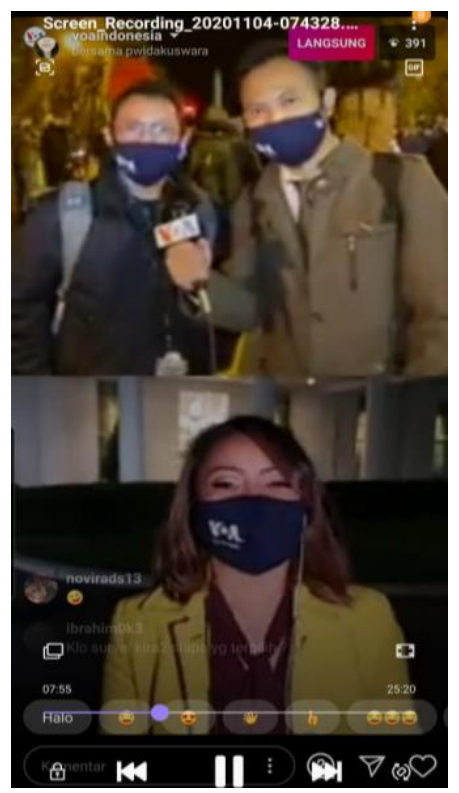

Sumber: Tangkapan layar live Instagram @voaindonesia (2020)

\section{Gambar 7. Live report bersama di Washington DC dan Los Angeles}

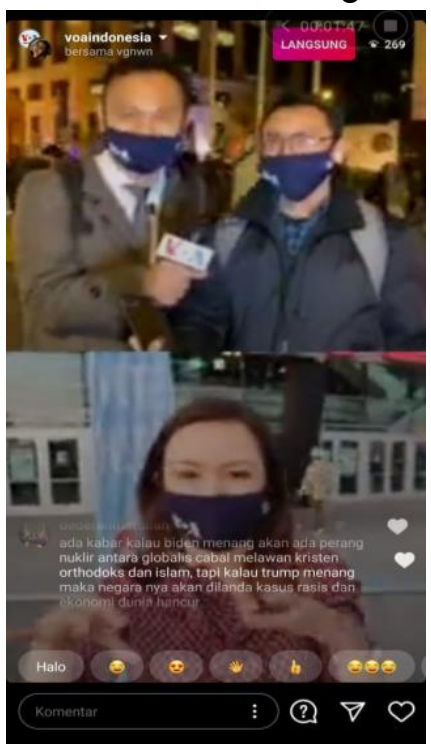

Sumber: Tangkapan layar live Instagram @voaindonesia (2020)

Karakter live Instagram tidak dapat diakses kembali oleh netizen apabila live Instagram telah berakhir, namun rekaman reportase 
menggunakan live Instagram dapat diunggah kembali pada Instagram feed berupa IGTV. Hal ini memungkinkan bagi pengguna Instagram yang tidak menonton saat live report di live Instagram, dapat menyaksikan melalui Instagram TV yang diunggah pada Instagram feed. Fitur-fitur pada Instagram menjadi kelebihan tersendiri dibanding media televisi dan radio, karena untuk media televisi dan radio merupakan media sekali pandang dengar sehingga jika live report sudah disiarkan sementara pemirsa/pendengar tertinggal acaranya maka tidak dapat mengakases kembali. Sedangkan pada media baru, dalam hal ini instagram, fitur-fitur yang disajikan dapat saling mendukung dan memungkinkan untuk diunggah dan ditonton kembali.

Hasil pengamatan pada live Instagram berikutnya, masih di hari yang sama tanggal 4 November 2020 sekitar jam 10.00 wib, Jurnalis VOA Indonesia yang berada di Washington DC kembali melakukan live Instagram kolaborasi namun berkolaborasi dengan Radio Most di Indonesia. Dengan demikian pengguna Instagram baik yang mem-follow akun @voaindonesia maupun Radio Most sama-sama dapat menyaksikan laporan langsung dari jurnalis VOA dan dapat menyampaikan pertanyaan apabila ada yang ingin ditanyakan. Artinya interaksi terjadi antara jurnalis VOA Indonesia, penyiar radio Most dan para follower akun Instagram VOA dan Radio Most @mostradio1058. Hal ini menjadi kelabihan Instagram yang memungkinkan terjadi interaksi yang cukup komplek antara beberapa media dan netizen, sehingga membuat media Instagram sebagai media yang sangat interaktif, dapat terjadi komunikasi timbal balik antara komunikator dan komunikan yang dimediasi oleh fitur live Instagram, berbeda dengan media televisi dan radio yang merupakan media satu arah.

Pengamatan pada saat live Instagram, kualitas visual kurang baik dan kurang stabil, beberapa gambar tidak fokus karena signal internet kurang stabil. Selain itu jika ditinjau dari kualitas komposisi 
gambar, dibelakang penyiar radio berdiri orang yang menjadi background kurang bagus karena keberadaan orang tersebut tidak ada fungsinya secara visual (gambar 8), namun demikian hal-hal seperti ini dapat ditolerir untuk media sosial.

Gambar 8. Live Instagram Kolaborasi antara Radio Most dengan VOA Indonesia

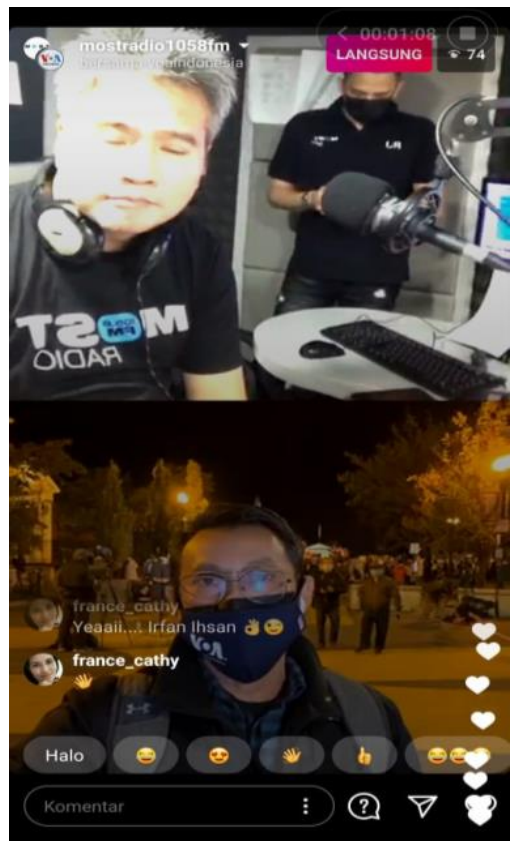

Sumber: Tangkapan layar live Instagram @mostradio1058fm (2020)

Berbeda bila jurnalis VOA Indonesia melakukan live report, dalam konsep live report televisi, gambar orang berseliweran dengan tingkah yang kadang lucu dan berusaha mengganggu (melambaikan tangan atau ekspresi lucu) kadang dianggap menjadi background noise visual yang dapat menganggu fokus perhatian penonton. Disisi lain background situasi ini penting untuk menggambarkan keaslian suasana saat live report dari lokasi peristiwa. Media televisi mengondisikan gambar harus bagus, tidak ada noise visual dengan diantisipasi pada saat akan melakukan live report televisi. Sebagai contoh anggota tim produksi lain menjaga kondisi sekitar agar gambar tidak bocor. Sementara di media sosial, justru karakternya berbeda, hal-hal diluar prediksi kadangkala 
menjadi unsur menarik dan unik yang bisa dikatakan sebagai "gimik" dalam live report, yang kadang justru menarik dan menghibur bagi audiens media sosial.

Dari beberapa contoh live report yang dilakukan menggunakan live Instagram oleh beberapa media tersebut, dapat dipahami bahwa praktek-praktek jurnalistik terus mengalami perubahan dan perkembangan. Media baru dan media sosial mendorong jurnalis untuk menerapkan mobile journalism dalam memproduksi dan menyajikan berita. Dari pengamatan dan pembahasan penerapan mobile journalism pada live report menggunakan fitur live Instagram dapat dirangkum bahwa:

1. Dengan adanya media baru, penerapan mobile journalism dalam live report menggunakan live Instagram, terjadi perubahan proses produksi dalam melakukan live report, yang biasanya membutuhkan banyak tim dan persiapan yang lebih rumit karena menggunakan OBVan, kini dapat dilakukan secara lebih sederhana bahkan dapat dilakukan sendiri oleh jurnalis menggunakan smartphone yang lebih portabel dan fleksibel, sehingga lebih mudah, murah, dan sederhana persiapannya, serta live report dapat dilakukan oleh reporter kapanpun dan dimanapun secara real time. Live report bersama dapat dilakukan menggunakan live instagram oleh dua reporter di dua lokasi secara bersamaan dengan menampilkan double frame, bahkan dapat dilakukan secara bergantian dan estafet oleh para jurnalis di beberapa lokasi berbeda secara bergantian.

2. Gaya, gesture dan bahasa live report menggunakan live Instagram mengalami pergerakan menyesuaikan karakter media sosial dan segmentasi audiens. Bahasa live report tidak terlalu formal.

3. Fitur komentar dan like mengakomodir sifat yang interaktif dan demokratis, memungkinkan masyarakat berkomentar dan memberikan pendapat. 
4. Makin bertumbuhnya pengguna aktif media sosial maka media sosial dapat menjadi medium yang signifikan untuk publikasi berita terutama untuk mencapai target sasaran audiens pengguna aktif media sosial.

\section{Referensi}

Hootsuit (We Are Social): Indonesia Digital Report 2020. Laporan Global Digital Reports 2020

Lokadata (2019). 10 Negara dengan Pengguna Instagram terbanyak. [Web page]. Retrieved from https://lokadata.beritagar.id/chart/preview/10-negaradengan-pengguna-instagram-terbanyak-1555736663

Lydersen, A. Busingye. (2020). Mojo! Telling the Story of Mobile Journalism, Through a mobile phone, to make a mobile audience. Departmenet of Media and Communication Faculty of Humanities. University of Oslo.

Maccise. D Larrea., \& Marai, Montaser. Mobile Journalism. Aljazeera Media Training \& Development Program

NapoleonCat. (2020). Instagram users in United States of America Januari 2020. [Web page]. Retrieved from https://napoleoncat.com/stats/instagramusers-in-united_states_of_america/2020/01

Quinn, Stephen. (2012). Mojo-Mobile Journalisme In Asian Region. Singapure: Konrad-Adenauer_Stiftung

abcnews. [@abcnews]. (2020, November 4h). Live report kondisi pemilu di Amerika [Live Instagram]. Retrived from https://www.instagram.com/abcnews/?hl=en

nbcnews [@nbcnews]. (2020, November $4^{\text {th }}$ ). Live report kondisi pemilu di Amerika [Live Instagram]. Retrived from https://www.instagram.com/nbcnews/?hl=en

voaindonesia [@voaindonesia]. (2020, November $4^{\text {th }}$ ). Live report kondisi pemilu di Amerika [Live Instagram]. Retrived from https://www.instagram.com/voaindonesia/?hl=en

mostradio1058fm [@mostradio1058fm] (2020, November 4 $\left.{ }^{\text {th }}\right)$, Most Radio bersama VOA Indonesia. [Live Instagram]. Retrived from https://www.instagram.com/mostradio $1058 \mathrm{fm} /$ ?hl=en 


\section{Profil Penulis}

Diyah Ayu Karunianingsih. Dosen Jurnalistik pada Program Studi Manajemen Produksi Berita - Jurusan Penyiaran Sekolah Tinggi Multi Media "MMTC" Yogyakarta, Kementerian Komunikasi dan Informatika RI. Alumni Jurusan Penyiaran STMM \& Kajian Budaya dan Media Universitas Gadjah Mada. Tertarik dengan bidang keilmuan Komunikasi, Jurnalistik, Broadcasting, Cultural Studies, Media dan Gender. 